\title{
ILEGITIMIDADES NA FICÇÃO DE ROBERTO BOLAÑO OS FILHOS DA OUTRA
}

\author{
Renata Farias de Felippe \\ UFSM
}

RESUMO: Contar as margens/nas margens, uma das reincidências da chamada literatura pós-moderna, é também um traço proeminente da ficção do escritor Roberto Bolaño. A sua obra ficcional — cuja irrupção se dá após o denominado "boom" da literatura latino-americana — aponta para um outro entre-lugar, distanciado tanto da tendência fantástica que deu visibilidade à literatura produzida na América hispânica, quanto da vertente que, debruçada sobre a própria literatura, questiona os limites da linguagem. Ficção circunscrita sob o signo do exílio e da inadequação, na obra de Bolaño as personagens estabelecem laços afetivos/familiares provisórios, (i)legítimos e é nesse âmbito que irrompem maternidades excêntricas, cujas contingências e instabilidades direcionam ao queer. Pensar as representações maternas/maternais como um locus de transitoriedades (i)legitimadas pelo afeto é o objetivo desta exposição.

PALAVRAS-CHAVE: Entre-lugares. Maternidades. Teoria queer.

\section{ILLEGITIMACIES IN ROBERTO BOLAÑO FICTION}

ABSTRACT: To count the margins/in the margins, one of the so-called relapses of post-modern literature is also a prominent feature of the fiction by the writer Roberto Bolaño. His fictional work — whose irruption takes place after the "boom" of Latin American Literature — points out to another in-between place, distanced both from the fantastic trend that gave visibility to the literature produced in Spanish America as well as from Metaliterature which questions the limits of language. As a fiction circumscribed under the sign of exile and inadequacy, in the work of Bolaño the characters establish provisional, (i) legitimate emotional/family ties, and it is in this context that eccentric motherhood erupts, whose contingencies and instabilities drive to the queer. To consider maternal representations as a locus of transitorities (i)legitimated by the affection is the goal of this paper.

KEYWORDS: In-between places. Motherhood. Queer theory.

Renata Farias de Felippe |renatfelippe@yahoo.com.br | é professora do Departamento de Letras Vernáculas da Universidade Federal de Santa Maria. 


\title{
ILEGITIMIDADES NA FICÇÃO DE ROBERTO BOLAÑO OS FILHOS DA OUTRA
}

\author{
Renata Farias de Felippe
}

O "segundo lugar na fila": de acordo com o crítico Silviano Santiago - no já canônico ensaio "O entre-lugar do discurso latino-americano" (1978) - essa seria a posição da cultura latino-americana no âmbito da cultural do ocidente, condição que envolveria uma postura reativa. Segundo o autor:

\footnotetext{
guardando seu lugar na segunda fila, é no entanto preciso que [a cultura latinoamericana] assinale sua diferença, marque sua presença, uma presença muitas vezes de vanguarda. [...] Falar, escrever, significa: falar contra, escrever contra. ${ }^{1}$
}

Se a condição de ex-colônia legou a secundariedade à cultura do continente, esse "local", de acordo com Santiago, é pleno de possibilidades, propício à recriação e mesmo ao vanguardismo. O lugar ocupado pela América Latina "no mapa da civilização ocidental", portanto, é delineado por um movimento "de desvio da norma", processo necessariamente "ativo e destruidor". 2 $\mathrm{A}(\mathrm{s})$ outridade(s), mais do que assinalar a(s) diferença(s), demonstra $(\mathrm{m})$ que os extremos centro/margem não são referenciais fixos, mas também construções e, como tais, sujeitas ao deslocamento e ao mútuo contágio.

Trinta e quatro anos após a publicação do ensaio seminal de Santiago, a crítica Florencia Garramuño aponta para o processo de "glamourização" da margem que, de acordo com a autora, seria uma reincidência da literatura e da arte modernas. A perspectiva glamourizada reduziria a margem a um "estar fora" relacionado a um único centro e a associaria a um espaço "eminentemente antidisciplinário", autônomo e, por isso mesmo, glamourizado. Para Garramuño, a "nova noção de margens não apela a um fora, mas, pelo contrário, a uma porosidade e a uma instabilidade, a uma errância radical que interrompe essas oposições." ${ }^{3}$

\footnotetext{
1 SANTIAGO, Silviano. O entre-lugar do discurso latino-americano. In: Uma literatura nos trópicos: ensaios sobre dependência cultural. 2. ed. Rio de Janeiro: Rocco, 2000, p. 16-17. Grifo nosso.

Ibidem, p. 16.

3 GARRAMUÑO, Florencia. A experiência opaca: literatura e desencanto. Trad. Paloma Vidal. Rio de Janeiro: Ed. UERJ, 2012, p. 88.
} 
A experiência da marginalidade como um locus de errâncias tem na obra de Roberto Bolaño - escritor chileno exilado na Espanha e falecido em 2003 uma materialização. Fenômeno editorial e nome apontado por Susan Sontag como um dos maiores expoentes da literatura latino-americana recente, a obra de Bolaño é, ao mesmo tempo, resultado e corporificação de uma série de desvios e de marginalidades. As errâncias que atravessam a sua produção permitem pensar o entre-lugar, de onde aquela irrompe, como um espaço dinâmico. No caso dos contos "El Ojo Silva" e, especialmente, "Prefiguración de Lalo Cura", da coletânea Putas asesinas (2001), a(s) outridade(s) extrapola $(m)$ o terreno movediço do(s) entre-lugar(es), o que permite aproximálo(s) e analisá-lo(s) também a partir de uma perspectiva queer. ${ }^{4}$

Reconhecido como ficcionista nos países de língua espanhola a partir dos anos 90 - quando vivia na Espanha, onde faleceu - a trajetória literária de Roberto Bolaño inicia-se pela poesia, quando o escritor vivia ainda no México, nos anos 70. O autor foi um dos porta-vozes do denominado Infrarrealismo, movimento pós-vanguardista mexicano, definido anos mais tarde por Bolaño "como una especie de Dadá a la mexicana". Os infrarrealistas produziram, sobretudo, poemas e manifestos e se opunham, em especial, aos chamados "poetas funcionários", reunidos em torno de Octavio Paz. ${ }^{5}$ Ainda que declarasse a preferência pelo gênero poético, é na prosa que o autor adquire reconhecimento ao ser publicado por grandes editoras espanholas, o que não diluiu a sua visão áspera e desencantada sobre o latino-americanismo e sobre a instituição literária. O "desencanto" ${ }^{6}$ que lhe é característico, é

4 O termo queer, que pode ser traduzido como estranho, talvez ridículo, excêntrico, raro, extraordinário é também uma expressão pejorativa com que são designados homens e mulheres homossexuais. A expressão foi tomada e refuncionalizada por uma vertente dos movimentos LGBT para qualificar uma postura contrária a toda espécie de normalização/normatização. O queer, portanto, representa claramente a diferença que não quer ser assimilada ou tolerada e, nesse sentido, sua forma de ação é muito mais transgressiva e perturbadora (Cf. LOURO, Guacira Lopes. Um corpo estranho: ensaios sobre sexualidade e teoria queer. Belo Horizonte: Autêntica, 2008, p.38-39). Adiante, nos deteremos sobre esse conceito.

5 Sobre a postura iconoclasta do escritor, Chiara Bolognese revela que "Bolaño utilizó muchos episodios de su primera 'época rebelde' para armar su ficción. En particular esto se nota en las aventuras de los poetas realvisceralistas mexicanos, protagonistas de Los detectives salvajes, quienes están muy orgullosos de pertenecer a la otra cara del universo cultural y se dedican a la vida bohemia típica de cierta clase de artista y de intelectual, suscitando el desprecio de 'los integrados'." BOLOGNESE, Chiara. Roberto Bolaño y sus comienzos literarios: el infrarrealismo entre realidad y ficción. Acta Literaria, Barcelona, n. 39, Il sem. 2009, p.138.

6 De acordo com Florencia Garramuño, o desencanto seria uma espécie de situação emocional atravessada pelo cinismo, o que não sugere, necessariamente, "morte e inação, mas desconfiança, desilusão, desengano e até desesperança e desalento" diante das mudanças promovidas pela modernização irrefreável no âmbito da cultura e da arte. Cf. GARRAMUÑO, Florencia. A experiência opaca, op. cit., p. 57-58. 
insistentemente reiterado através de suas personagens, figuras solitárias e inadaptáveis cuja estranheza e esvaziamento ideológico dinamizam o próprio relato.

Circunscrita à estranheza - seja pela incursão do autor na poesia, seja pela abordagem apartidária e cética da problemática ditatorial na América Latina, seja pela militância pós-vanguardista, seguidas pela consagração mercadológica - a obra de Bolaño distancia-se estilisticamente e ideologicamente tanto dos autores do denominado boom latino-americano quanto da produção de dois de seus mais conhecidos compatriotas: Pablo Neruda e Isabel Allende, o que é expresso pelo próprio autor no conto "Carnet de baile". ${ }^{7}$ A trajetória literária do escritor é, portanto, um itinerário de desvios e de peculiaridades que direcionam a uma espécie de antinormatização que nos permite associar a problemática do entre-lugar à perspectiva queer, se partirmos do pressuposto de que "queer é um jeito de pensar que não aspira o centro nem o quer como referência, [...] que assume o desconforto da ambiguidade, do 'entre lugares', do indecidível". ${ }^{8}$ Ao encarar a estranheza e a instabilidade como locais de circunscrição e de conhecimento, a teoria queer produz uma espécie de "reviravolta epistemológica que transborda, inclusive, o terreno da sexualidade. Ela provoca e perturba as formas convencionais de pensar e de conhecer", já que a própria "sexualidade, polimorfa e perversa, é ligada à curiosidade e ao conhecimento". ${ }^{9}$ Para Larissa Pelúcio, a teoria queer pode ser entendida como um conjunto de enunciações teóricas reconhecidas como "subalternas justamente pelo enfrentamento teórico, metodológico, ético e epistemológicos que fazem aos saberes hegemônicos" de toda a espécie. ${ }^{10}$

\footnotetext{
7 No conto "Carnet de baile" (2001), em meio a uma alucinação, o narrador chega a nivelar o espectro do poeta chileno aos de Hitler e de Stalin, associando Neruda ao signo da opressão: "47 Lo confieso: no puedo leer el libro de memorias de Neruda sin sentirme mal, fatal. Qué cúmulo de contradicciones. Qué esfuerzos para ocultar y embellecer aquello que tiene El rostro desfigurado. Qué falta de generosidad y qué poco sentido del humor. 48 Hubo una época felizmente ya pasada de mi vida en que veía por el pasillo de mi casa a Adolf Hitler. Hitler no hacía nada más que caminar pasillo arriba y pasillo abajo y cuando pasaba por la puerta abierta de mi dormitorio ni siquiera me miraba. Al principio pensaba que era (¿qué otra cosa podía ser?) el demonio y que mi locura era irreversible. 49 Quince días después Hitler se esfumó y yo pensé que el siguiente en aparecer seria Stalin. Pero Stalin no apareció." BOLAÑO, Roberto. Carnet de baile. In: Putas asesinas. Barcelona: Editorial Anagrama, 2001, p. 117. Já sobre Isabel Allende, Bolaño revela: "[...] Ilamarla escritora es darle cancha. Ni siquiera creo que Isabel Allende sea una escritora, es una escribidora." Reproduzido em Crónica.com.mx, 20 maio 2002.

8 LOURO, Guacira Lopes. Um corpo estranho, op. cit., p. 7-8.

9 Ibidem, p. 51

${ }^{10}$ Entre os questionamentos realizados por tal episteme está não apenas a heteronormatividade, como as próprias reivindicações LGBTT, as identidades e a educação. Cf. PELÚCIO, Larissa. Subalterno quem, cara pálida? Apontamentos às margens sobre pós-colonialismos, feminismos e estudos queer. Contemporânea, São Carlos, v. 2, n. 2, p. 395-418, jul./dez. 2012.
} 
O "enfrentamento" é exatamente o que as narrativas de Bolaño contam e o que a própria mitologia em torno do nome do autor revela. A representação da experiência de sujeitos fronteiriços, materializada em sua ficção, remete a uma dinâmica "fortemente política", se considerarmos a vivência em movimento como "uma ampliação nas possibilidades de ser e de viver que permite encarar a diversidade sob um viés produtivo, ou seja: o processo de se 'fazer' como sujeito, de acordo com a perspectiva queer, pode ser experimentado com intensidade." ${ }^{11}$ Nos contos "El Ojo Silva" e "Prefiguración de Lalo Cura", as múltiplas travessias realizadas e os não-lugares ocupados pelos protagonistas errantes permitem o repensar não apenas das identidades individuais como da própria latinoamericanidade. Ser latino-americano na sociedade pósmoderna e globalizada é viver tanto o entre-lugar quanto a vacância, tanto a margem quanto o cosmopolitismo (do pobre). ${ }^{12}$

No conto "El Ojo Silva”, o protagonista “Mauricio Silva, llamado el Ojo" ${ }^{13}$, incorpora uma série de marginalidades: exilado chileno; homossexual exilado inclusive entre os exilados que viviam no México dos anos 70; latino-americano sem pátria após o período da abertura; sujeito que acrescenta à própria marginalidade a condição de foragido e de mãe circunstancial. Todas essas diferenças inassimiláveis sabotam definições, direcionam à pós-identidade, bem como engendram a reconsideração dos referenciais literários. Em termos de literatura latino-americana pós-moderna, o cânone ocidental já não parece oferecer uma referência de distanciamento, posição talvez desempenhada, hoje, pelo entre-lugar.

Já no primeiro parágrafo do conto, o narrador em primeira pessoa sintetiza o conteúdo da narrativa, oferece ao leitor uma espécie de "retrato" de geração que sintetiza o trauma da vivência ditatorial.

${ }^{11}$ Cf. LOURO, Guacira Lopes. Um corpo estranho, op. cit., p. 23.

12 No ensaio "O cosmopolitismo do pobre", Silviano Santiago chama a atenção para a necessidade de o desfavorecido tornar-se cosmopolita em sua busca por melhores condições de vida. Na sociedade globalizada, o multiculturalismo latino-americano estaria longe do que o crítico denominou "multiculturalismo cordial", presente em obras canônicas como Iracema e Gabriela, cravo e canela. Santiago desenvolve a ideia do "efeito bumerangue", que atiraria o multiculturalismo do séc. XIX e parte do século XX de volta para a Europa ou para os Estados Unidos (nesse caso, como uma espécie de resposta involuntária ao imperialismo cultural). O fenômeno de emigração na cidade de Governador Valadares (MG) exemplificaria essa dinâmica. Talvez os argumentos do crítico pareçam datados se considerarmos um fenômeno recente, que é o delineamento do Brasil como uma espécie de nova metrópole em relação aos países sul-americanos e do continente africano, tema explorado, inclusive, pela minissérie brasileira Destino: São Paulo (2012), produzida pela HBO. Cf. SANTIAGO, Silviano. O cosmopolitismo do pobre. In: O cosmopolitismo do pobre: crítica literária e crítica cultural. Belo Horizonte: UFMG, 2008, p. 45-63.

${ }^{13}$ BOLAÑO, Roberto. El Ojo Silva. In: Putas asesinas, op. cit., p. 5-13. 
Lo que son las cosas: Mauricio Silva, llamado el Ojo, siempre intentó escapar de la violencia, [...] pero de la violencia, de la verdadera violencia, no se puede escapar, al menos no nosotros, los nacidos en Latinoamérica en la década de los cincuenta, los que rondábamos los veinte años cuando murió Salvador Allende. $^{14}$

Nas primeiras linhas de "El Ojo Silva", o narrador homodiegético situa o protagonista em uma geração para, em seguida, assinalar as diferenças, as peculiaridades e as sucessivas marginalidades incorporadas pelo personagem:

Por aquellos días se decía que el Ojo Silva era homosexual. Quiero decir: en los círculos de exilados chilenos corría ese rumor, en parte como manifestación de maledicencia y en parte como un nuevo chisme que alimentaba la vida más bien aburrida de los exiliados, gente de izquierdas que pensaba, al menos de cintura para abajo, exactamente que la gente de derecha que en aquel tempo se enseñoreaba de Chile. $^{15}$

No fragmento, a diferença em torno de Ojo Silva é explorada pelo narrador exatamente para acentuar o conservadorismo e a intolerância da esquerda chilena de então, no que diz respeito à sexualidade e às suas práticas. Ao apontar a postura discriminatória da esquerda da época, a conotação política do conto ultrapassa a polarização ideológica, o que pode ser apontado como uma marca autoral de Bolaño, cuja ficção pulveriza todos os maniqueísmos. Na narrativa, o drama identitário envolve a postura política, a origem, as práticas de gênero, questões que se (ir) resolvem através da incorporação dos "entre-lugares" e do indecidível. Após o protagonista assumir a sua homossexualidade para o narrador, ambos os personagens mostram-se críticos aos seus "pares":

Recuerdo que terminamos despotricando contra la izquierda chilena y que en algún momento yo brindé por los luchadores chilenos errantes, una fracción numerosa de los luchadores latinoamericanos errantes, entelequia compuesta de

\footnotetext{
${ }^{14}$ Ibidem, p. 5. "Vejam como são as coisas: Maurício Silva, vulgo o Olho, sempre tentou escapar da violência, [...] mas da violência, da verdadeira violência, não se pode escapar, pelo menos não nós, os nascidos na América Latina na década de cinquenta, os que rondávamos os vinte anos quando morreu Salvador Allende." O Olho Silva. In: Putas assassinas. Trad. Eduardo Brandão. São Paulo: Companhia das Letras, 2008, p. 11. As demais traduções são todas da edição brasileira.

15 Ibidem, p. 6. "Naqueles dias dizia-se que o Olho Silva era homossexual. Quer dizer: nos círculos de exilados chilenos corria o boato, em parte como manifestação da maledicência, em parte como uma nova fofoca que alimentava a vida bastante chata dos exilados, gente de esquerda que pensava, em todo caso da cintura para baixo, exatamente como a gente de direita que naquele tempo se apoderava do Chile." (p. 12)
} 
huérfanos que como su nombre indica, erraban por el ancho mundo ofreciendo sus servicios al mejor postor, que casi siempre, por lo demás, era el peor. ${ }^{16}$

O brinde dos personagens é uma espécie de ode às travessias e aos heróis inadaptáveis, órfãos que, se não são propriamente paradigmas, nos oferecem a "distância e o horizonte, o 'não' e o impulso para se caminhar."17

Ao reencontrar o "estoico e amable" Ojo Silva - "una especie de chileno ideal, [...] un ejemplar que nunca había abundado mucho en Chile pero que sólo allí se podía encontrar" - na Alemanha atual, o narrador fica a par da iniciação do protagonista na violência inerente à condição latino-americana. Será na Índia - uma outra margem - que a injustiça se apresentará da forma mais cruel e arbitrária ao pacato Ojo Silva, o que desperta a sua faceta justiceira. Em um dos seus trabalhos como fotógrafo, o protagonista se depara com a existência de um ritual clandestino, no qual ocorre a emasculação de crianças. Diante de tamanha arbitrariedade, o personagem torna-se não apenas um justiceiro, mas, de acordo com as suas próprias palavras, transforma-se em mãe:

Y entonces el Ojo se convertió en outra cosa, aunque la palabra que el empleó no fue "outra cosa" sino "madre". [...] Lo que sucedió a continuación de tan repetido es vulgar: la violencia de la que no podemos escapar. El destino de los latino-americanos nacidos en la década de los cincuenta. [...] Lo único cierto es que hubo violencia [...]. Recuerda con viveza la sensación de exaltación que creció en su espiritu [...]. También: la sombra que proyectaba su cuerpo y las sombras de los dos niños que llevaba de la mano sobre los muros descascarados. ${ }^{18}$

A "maternidade" de Ojo Silva, exercida de modo necessariamente urgente e clandestino, é, para o personagem, uma experiência temível, desafiadora e,

${ }^{16}$ Ibidem, p. 6. "Lembro-me que acabamos metendo o pau na esquerda chilena e que a certa altura fiz um brinde aos lutadores chilenos errantes, uma fração numerosa dos lutadores latino-americanos errantes, mítica ficção composta por órfãos que, como o nome indica, erravam pelo vasto mundo oferecendo seus serviços ao melhor proponente, que quase sempre, aliás, era o pior." (p. 13-14)

17 LARROSA, Jorge apud LOURO, Guacira Lopes. Um corpo estranho, op. cit., p. 24. No já mencionado conto "Carnet de baile", o narrador em primeira pessoa se mostra solidário a uma linhagem peculiar de escritores, o que reitera a estranheza e a inadaptação como os locais de circunscrição da obra de Bolaño: "Pienso en Beltrán Morales, pienso en Rodrigo Lira, pienso en Mario Santiago, pienso en Reinaldo Arenas. Pienso en los poetas muertos en lo potro de tortura, en los muertos de sida, de sobredosis, en todos los que creyeron en el paraíso latinoamericano y murieron en el infierno latinoamericano. Pienso en esas obras que acaso permitan a la izquierda salir del foso de la vergüenza y la inoperancia." BOLAÑO, Roberto. Carnet de baile, op. cit., p. 118.

18 BOLAÑ̃, Roberto. El Ojo Silva, op. cit., p. 11. "Então o Olho se transformou noutra coisa, se bem que a palavra que ele empregou não foi 'outra coisa' e sim 'mãe'. [...] O que aconteceu em seguida, de tão repisado é vulgar: a violência da qual não podemos escapar. O destino dos latino-americanos nascidos na década de cinquenta. [...] O que é certo é que houve violência [...]. Lembra-se com vivacidade da sensação de exaltação que cresceu em seu espírito [...]. Também: a sombra que seu corpo projetava e as sombras dos dois meninos que levava pela mão nas paredes descascadas." (p. 22) 
como veremos, circunstancial:

En sus pesadillas, no obstante, el Ojo soñaba que en mitad de la noche aparecía la policía india y lo detenían con acusaciones indignas. Solía despertar temblando. Entonces se acercaba de las esterillas en donde dormían los niños y la visión de éstos le daba fuerzas para seguir, para dormir, para levantarse. [...]. Después llegó la enfermedad a la aldea y los niños murieron. Yo también quería morirme, dijo el Ojo, pero no tuve esa suerte. ${ }^{19}$

Em seu itinerário, o protagonista não se depara apenas com a violência inerente à sua condição - latino-americano nascido na década de 50 -, mas também com aquela que espreita a dinâmica (forçosamente) cosmopolita do pobre. ${ }^{20} \mathrm{O}$ deslocamento de Ojo Silva, impulsionado por questões, primeiramente políticas, mas também de sobrevivência (exílio no México), passa a ser uma condição permanente e que, no caso do resgate das crianças, assume conotações trágicas. Em outros termos, a salvação dos "filhos" de Ojo Silva não está a salvo do "perde-ganha da vida cosmopolita": ao mesmo tempo em que Ojo experiencia a coragem e a maternidade (ganhos), ele também perde os filhos para a "doença", um dos males da pobreza onipresente nos países em desenvolvimento. Diante da orfandade e das perdas, resta ao protagonista o relato ao narrador e o lamento.

Aquella noche, cuando volvió a su hotel, sin poder dejar de llorar por sus hijos muertos, por los niños castrados que él no había conocido, por su juventud perdida, por todos los jóvenes que ya no eran jóvenes y por los jóvenes que murieran jóvenes, por los que lucharan por Salvador Allende y por los que tuvieron miedo de luchar por Salvador Allende, [...]. Y luego siguió llorando sin parar. ${ }^{21}$

19 Ibidem, p. 12. "Mas nos pesadelos do Olho aparecia a polícia indiana no meio da noite e o detinham com acusações indignas. Costumava acordar tremendo. Então se aproximava das esteiras onde os meninos dormiam e a visão deles lhe dava forças para continuar, para dormir, para se levantar. [...] Depois a doença chegou à aldeia e os meninos morreram. Eu também queria morrer, disse o Olho, mas não tive essa sorte." (p. 24)

20 De acordo com Silviano Santiago, "o cosmopolitismo do pobre" seria a decorrência de um "novo expediente do capital transnacional", o efeito do fluxo migratório dos grupos de desprivilegiados dispostos a exercer - muitas vezes de forma clandestina - as funções domésticas/manuais nas metrópoles pós-modernas e transnacionais. Nessa travessia, esses grupos estão sujeitos ao perdeganha da experiência migratória: dos referenciais linguísticos e culturais do país de origem (perdas); da própria sobrevivência ("ganho"). Essa dinâmica delineia um outro multiculturalismo, causador de uma espécie de "desnacionalização" gradual, seja no âmbito do espaço urbano, seja no da política. Cf. SANTIAGO, Silviano. O cosmopolitismo do pobre, op. cit., p. 54-61.

${ }^{21}$ BOLAÑO, Roberto. El Ojo Silva, op. cit., p. 13. "Naquela noite, quando voltou ao hotel, sem conseguir parar de chorar por seus filhos mortos, pelos meninos castrados que não tinha conhecido, por sua juventude perdida, por todos os jovens que já não eram jovens e pelos jovens que morreram jovens, pelos que lutaram por Salvador Allende e pelos que tiveram medo de lutar por Salvador Allende, [...]. E continuou chorando sem parar." (p. 25) 
A maternidade queer, exercida e vivida à margem, desvinculada do paradigma burguês, é também abordada, sob a ótica filial, em um outro conto de Putas asesinas: "Prefiguración de Lalo Cura". Nele, o narrador é o próprio Lalo do título, matador profissional colombiano nascido em Medéllin, no bairro de Empalados. Filho de um padre renegado de procedência incerta - "latinoamericano era. Pobre como las ratas" - e da atriz pornô Connie Sanchéz, o que o protagonista nos conta é a sua origem, marcada pela ausência do referencial paterno. O personagem, no entanto, encontra uma maneira de enfrentar o fantasma de sua bastardia assistindo aos filmes estrelados por sua mãe, Connie, durante a gravidez. Diante da ausência de um pai, a tentativa de reconstruir as próprias origens tem como referenciais os filmes pornográficos, produtos degradados da denominada cultura de massas.

[...] el Pajarito mira como hipnotizado la barriga de Connie. El misterio de la vida en Latinomérica. Como un pajarito delante de una serpiente. La Fuerza está conmigo, me dije, la primera vez que vi la película, a los diecinueve años, llorando a moco tendido [...]. Hubiera querido creer que las vergas que penetraron a mi madre se encontraron al final del sendero con mis ojos. Soñé con ello a menudo: mis ojos cerrados y translúcidos en la sopa negra de la vida. ${ }^{22}$

A reconstrução do passado individual, bem como a busca pelas raízes latino-americanas, são traumas que Lalo e, por extensão, os seus conterrâneos enfrentaram/enfrentam. A perturbação da "paz intrauterina" "nos une. Socialmente. Economicamente. Filosoficamente". A "quebra" do idílio entre o bebê e a progenitora - que, segundo Freud, insere o indivíduo na fase edipiana - no caso de Lalo, se dá antes mesmo da intrusão da linguagem e da figura paterna (no caso, inexistente), o que confere à violência em torno de suas origens um caráter acentuadamente perverso. O corpo da mãe, que Luce Irigaray define como o "corpo primeiro, o lar primeiro, o primeiro amor" ${ }^{23}$, é

22 Idem, Prefiguración de Lalo Cura. In: Putas asesinas, op. cit., p. 54. “[...] Pajarito olha como que hipnotizado para a barriga de Connie. O mistério da vida na América Latina. Como um passarinho diante de uma cobra. Eu tenho a Força, eu me disse da primeira vez que vi o filme, aos dezenove anos, chorando aos borbotões [...]. Eu gostaria de acreditar que os caralhos que penetraram minha mãe se encontraram no fim da trilha com os meus olhos. Sonhei com isso muitas vezes: meus olhos fechados e translúcidos na sopa negra da vida." Prefiguração de Lalo Cura. In: Putas assassinas, op. cit., p. 97. Em português a relação entre o pássaro e o personagem Pajarito não fica tão evidente. É interessante destacar a inversão de sentidos, já que o "pássaro", o "pajarito", é o ator que contracena com Connie grávida, o homem que "invade" o território intrauterino. Na passagem, o portador do falo assume também uma conotação ligada à fragilidade.

23 IRIGARAY, Luce apud STEVENS, Cristina. Maternidade e feminismo: diálogos na literatura contemporânea. In: _. (Org.). Maternidade e feminismo: diálogos interdisciplinares. Florianópolis/Santa Cruz do Sul: Ed. Mulheres/EDUNISC, 2007, p. 35. 
um espaço repetidamente violado e corrompido, à semelhança do que ocorreu com o continente latino-americano durante a colonização. A perseguição aos "filhos" da América Latina também foi uma (dura) realidade no período ditatorial. Na passagem destacada, a vida na América Latina é um mistério por ser uma irrupção ocorrida sob o signo da vulnerabilidade, à semelhança do letal encontro entre o pássaro (ser inerme e livre) e a cobra (signo do perigo, com frequente conotação fálica). Essa situação de impotência é acentuada pela imagem onírica de Lalo, que se vê como um feto de "ojos cerrados y translúcidos", mergulhado "en la sopa negra de la vida". O narrador-protagonista se vê, portanto, como um ser frágil e solitário em um ambiente hostil, como aquele que "fecha os olhos" quando confrontado com uma dura verdade: o corpo materno (a América Latina?) é um espaço submetido a inúmeras violações. A despeito de nossa "labuta", jamais seremos "filhos da santa", somente "filhos da outra", condição que confere à linhagem latino-americana um sentido inevitavelmente queer.

O processo de reconstrução das origens empreendido por Lalo tem mais um encontro com a estranheza, inerente a sua existência, quando o personagem confronta, mais uma vez, o seu passado. Já adulto e já matador, o protagonista procura Pajarito Gómez, que contracenara com sua mãe ainda gestante. No encontro, o diálogo entre Pajarito e o protagonista se aproxima da interlocução entre pai e filho, posições discursivas que, aliás, os personagens alternam.

\begin{abstract}
Has venido a matarme, Lalito, dijo. [...] Hasta donde cabe soy una persona normal. Por Doris tuve un cariño sincero, tu madre siempre encontró un amigo en mí, cuando eras pequeño nunca te hice daño. ¿Lo recuerdas? [...] En aquella época, cuando aún era joven, me costaba emplear la palabra matar. Nunca mataba: daba el billete, borraba, hundía [...]. Quemaba. Pero al Pajarito no lo quemé, sólo quería verlo y platicar un rato con él. [...] Cuando yo era niño, Connie, Monica, Doris, Bitrich, el Pajarito, [...] todos me llamaban así: Lalito. [...] Nunca pensé en matarte, dije, conservo todas tus películas [...]. Te dejaré dinero, Pajarito, para que vivas sin trabajar. Te compraré lo que quieras. ${ }^{24}$
\end{abstract}

\footnotetext{
${ }^{24}$ BOLAÑO, Roberto. Prefiguración de Lalo Cura, op. cit., p. 60-61. "Você veio me matar, Lalito, falou. [...] Na medida do possível, sou uma pessoa normal. Por Dóris tive um carinho sincero, sua mãe sempre encontrou um amigo em mim, quando você era pequeno, nunca fiz mal a você. Lembra? [...] Naquela época, quando ainda era moço, me custava empregar a palavra matar. Nunca matava: abotoava, apagava [...]. Queimava. Mas o Pajarito eu não queimei. Só queria vê-lo e conversar um pouco com ele. [...] Quando eu era menino, Connie, Mônica, Dóris, Bitrich, Pajarito, [...] todos me chamavam assim: Lalito. [...] Nunca pensei em matá-lo, falei, conservei todos os seus filmes [...]. Vou deixar um dinheiro, Pajarito, para que você viva sem trabalhar. Vou comprar o que você quiser." (p. 109).
} 
Pajarito trata o matador profissional, que conhecera ainda menino, pelo diminutivo, acentua a sua amizade com Connie, destaca o tratamento inofensivo dispensado à criança, como se fosse um "pai" ou um familiar tentando esboçar laços de afeto. Se a busca de Lalo foi movida, inicialmente, por vingança, ou ainda, empreendida no intuito de encontrar um "pai", o que o protagonista encontra é um semelhante, igualmente imerso na "sopa negra da vida"; uma figura do seu passado de quem o protagonista resolve cuidar, assumindo ele agora a posição paternal (ou fraternal). Ao mostrar-se solidário a Pajarito, Lalo acaba por se solidarizar com todos os

[j]óvenes mestizos, negros, blancos, indios, hijos de Latinoamérica cuya única riqueza era un par de huevos y un pene cuarteado por las intemperies o milagrosamente rosado quien sabe por qué extraños vericuetos de la naturaleza. [...] pollas monumentales en la vastedad y desolación de este continente. ${ }^{25}$

A solidão e a estranheza nivelam esses seres anódinos, anônimos, órfãos; essas mães, irmãos, pais e padrinhos circunstanciais construídos por Bolaño, figuras cujo única "riqueza" é a própria vulnerabilidade, condição que lhes impulsiona a cruzar tanto as fronteiras espaciais quanto as da "moralidade", sem medo, sem questionamento, sem culpa. Entre os escritores latino-americanos contemporâneos, Roberto Bolaño - a despeito do culto ou das acusações em torno de seu nome - parece entender como poucos a condição latino-americana pós-moderna, ao tornar a "bastardia" e o entre-lugar que nos caracterizam locais de circunscrição. Ao fazê-lo, o escritor - que se autodeclarava latino-americano e não, simplesmente chileno - parece erigir uma literatura alheia aos tributos e às filiações limitadoras, comprometida unicamente com os seus próprios e profícuos desvios.

\footnotetext{
${ }^{25}$ Ibidem, p. 58. "[j] ovens mestiços, negros, brancos, índios, filhos da América Latina cuja única riqueza era um par de ovos e um pênis maltratado pelas intempéries ou milagrosamente rosado sabe lá por que estranhos meandros da natureza. [...] pirocas monumentais na vastidão e na desolação deste continente." (p. 104)
} 